Viet Nam National University Ho Chi Minh City, Viet Nam
Science and Technology Development Journal
ISSN: 1859-0128
Volume 21: Issue 01 June 2018
Journal homepage: http://stdj.scienceandtechnology.com.vn

\title{
Extraction, isolation and characterization of depsidones from Usnea baileyi (Stirt.) Zahlbr collected from tree barks in Tam Bo Mountain of Di Linh, Lam Dong Province, Viet Nam
}

\author{
${ }^{1}$ Nguyen Van Kieu, ${ }^{2}$ Duong Thuc Huy ${ }^{*}$ \\ ${ }^{1}$ Natural Products Research Unit, Department of Chemistry, Faculty of Science, Chulalongkorn University, \\ Pathumwan, Bangkok, Thailand. \\ ${ }^{2}$ Department of Chemistry, Ho Chi Minh City University of Education, 280 An Duong Vuong Street, District 5, Ho \\ Chi Minh City, Viet Nam. thuchuy84@yahoo.com
}

\section{ARTICLE DETAILS}

History

Received: 05 April 2018

Accepted: 03 June 2018

Published: 20 June 2018

\section{Keywords}

Depsidones, Lichen,

Menegazziaic, Stictic acid, Usnea

baileyi

\begin{abstract}
Chemical data on the lichen Usnea baileyi are scarce. The current investigation reports the extraction, isolation and characterization of depsidones from this lichen collected in Lam Dong Province. Eight depsidones were isolated and elucidated, including methylstictic acid (1), stictic acid (2), cryptostictic acid (3), 8'-O-methylmenegazziaic acid (4), menegazziaic acid (5), 8'O-methylconstictic acid (6), constictic acid (7), and hypoconstictic acid (8). Multi chromatographic methods comprising normal phase silica gel column chromatography and thin layer chromatography were applied to the crude acetone extract to isolate and purify compounds 1-8. Their chemical structures were elucidated by spectroscopic analysis as well as comparing their data with ones in the literature.
\end{abstract}

(c) 2018 Viet Nam National University Ho Chi Minh City, Viet Nam under a Creative Commons Attribution-NonCommercial-ShareAlike 4.0

\section{Introduction}

Lichens are symbiotic associations comprised of a fungus and a photobiont partner (green alga and/or cyanobacteria). This unique organism produces numerous metabolites endowed with various biological activities Müller (2001); Boustie and Grube (2005). Among them, depsidone scaffold is a unique skeleton possessing many biological activities such as enzyme inhibition, cytotoxicity, and antiviral activities Müller (2001).

${ }^{*}$ Corresponding author's email address: thuchuy84@yahoo.com

Recommended citation: Kieu, Nguyen Van and Huy, Duong Thuc, (2018). Extraction, isolation and characterization of depsidones from Usnea baileyi (Stirt.) Zahlbr collected from tree barks in Tam Bo Mountain of Di Linh, Lam Dong Province, Viet Nam . Science and Technology Development Journal, 21(1): 24-31. 
Recent phytochemical studies on Vietnamese lichen afforded novel metabolites showing good bioactivity Duong et al. (2017); Nguyen et al. (2017). The fruticose lichen Usnea baileyi is widely grown in high-attitude forests of Vietnam. Two previous phytochemical studies on this lichen led to the isolation of several xanthones Yang et al. (1973), depsidones and depsides Yang et al. (1973); Din et al. (2010), along with usnic acid.

The current investigationreports on the extraction, isolation and characterization of depsidones from the lichen Usnea baileyi. Eight depsidones (1-8) (Figure 1) were isolated and structurally elucidated. Their chemical structures were elucidated by spectroscopic analysis as well as comparing their data with ones in the literature.

\section{Materials - Methodology}

\subsection{General experimental procedures}

The NMR spectra were measured on a Bruker Avance $\left(400 \mathrm{MHz}\right.$ for ${ }^{1} \mathrm{H} \mathrm{NMR}$ and $100 \mathrm{MHz}$ for ${ }^{13} \mathrm{C}$ NMR) spectrometers. Proton chemical shifts were referenced to the solvent residual signal of $\mathrm{CD}_{3} \mathrm{SOCD}_{3}$ at $\delta_{H}$ 2.50. The ${ }^{13} \mathrm{C}-\mathrm{NMR}$ spectra were referenced to the central peak of $\mathrm{CD}_{3} \mathrm{SOCD}_{3}$ at $\delta_{C} 39.52$. Thin layer chromatography (TLC) was carried out on pre-coated silica gel $60 \mathrm{~F}_{254}$ or silica gel $60 \mathrm{RP}-18$ $\mathrm{F}_{254} \mathrm{~S}$ (Merck Millipore, Billerica, Massachusetts, USA), and spots were visualized by spraying with $10 \%$ $\mathrm{H}_{2} \mathrm{SO}_{4}$ solution followed by heating. Gravity column chromatography was performed with silica gel 60 (0.040-0.063 mm, Merck Millipore, Billerica, Massachusetts, USA).

\subsection{Plant material}

Thallus of the lichen U. baileyi were collected from the tree barks in Tam Bo Mountain, Di Linh District, Lam Dong Province, Viet Nam in May 2015. The scientific name of this lichen was identified by Ms. Natwida Dangphui and Assistant Professor Dr. Ek Sangvichien, Lichen Research Unit, Department of Biology, Faculty of Science, Ramkhamhaeng University, Bangkok, Thailand.

\subsection{Extraction and isolation}

The air-dried lichen powder $(800.0 \mathrm{~g})$ was macerated with acetone at room temperature $(3 \mathrm{x} 10 \mathrm{~L})$, and the filtrate was evaporated until dryness to yield the crude acetone extract $(80.0 \mathrm{~g})$. This extract was washed three times with acetone to obtain a precipitate $\mathbf{P}(23.7 \mathrm{~g})$. The filtrated solution was further concentrated to yield the acetone extract Ac (56.2 g).

The precipitate $\mathbf{P}$ (23.7 g) was subjected to silica gel column chromatography (CC), and eluted with a solvent system of $\mathrm{CH}_{2} \mathrm{Cl}_{2}$ : $\mathrm{MeOH}: \mathrm{AcOH}$ (9.0: 0.2: 0.06) to afford three fractions: P1 (10.7 g), P2 (7.2 g), and P3 (5.8 g). Fraction P2 was applied in the same manner as fraction P1 to yield two fractions P2.1 (3.2 g) and P2.2 (3.8 g). Fraction P2.2 was further applied on CC, eluted with $n$-hexane: $\mathrm{CH}_{2} \mathrm{Cl}_{2}: \mathrm{AcOH}$ (9.0: 1.0: 0.1) to obtain three compounds: 1 (3.2 $\mathrm{mg}), \mathbf{4}(4.2 \mathrm{mg})$ and $\mathbf{6}(4.0 \mathrm{mg})$.

The acetone extract Ac (56.2 g) was applied to fast $\mathrm{CC}$, and eluted with $\mathrm{CH}_{2} \mathrm{Cl}_{2}$, EtOAc, acetone and MeOH to obtain four extracts: DC (31.2 g), EA (9.6 g), AC (6.5 g) and ME (4.6 g). Extract EA was washed with acetone to obtain the precipitate EA-P $(1.0 \mathrm{~g})$ and a filtrate. The solution was then evaporated to dryness to yield fraction EA-L $(7.8 \mathrm{~g})$. The precipitate EA-P was applied on normal phase silica gel $\mathrm{CC}$, and eluted with the solvent system $\mathrm{CH}_{2} \mathrm{Cl}_{2}: \mathrm{MeOH}$ : $\mathrm{AcOH}$ (9.0: 0.2: 0.06) to yield two compounds $2(506.2 \mathrm{mg})$ and $7(307.0 \mathrm{mg})$. Fraction EA-L was further separated by silica gel CC, eluted with the same solvent system to obtain three fractions EA-L1-3.The fraction EA-L3 (6.5 g) was fractionated into 


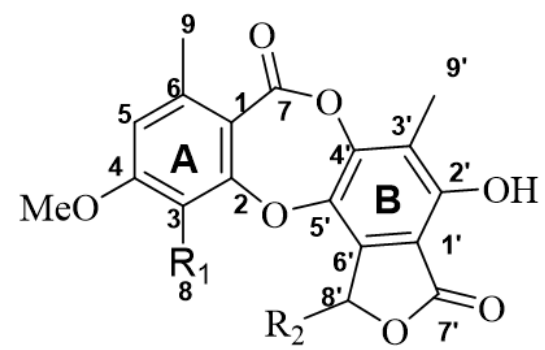

1 $\mathrm{R}^{1:} \mathrm{CHO}$

$2 \mathrm{R}^{1}$ : $\mathrm{CHO}$

$\mathrm{R}^{2}$ : OMe

$3 \mathrm{R}^{1}: \mathrm{CH}_{2} \mathrm{OH} \quad \mathrm{R}^{2}: \mathrm{OH}$

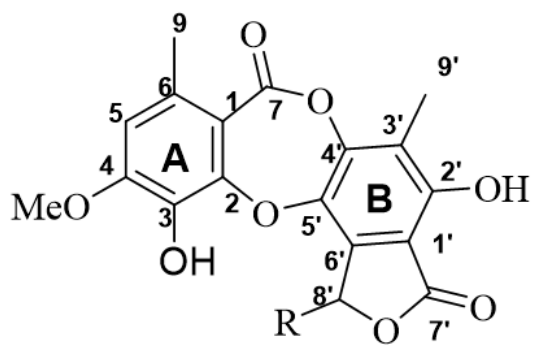

$4 \mathrm{R}: \mathrm{OMe}$

$5 \mathrm{R}: \mathrm{OH}$

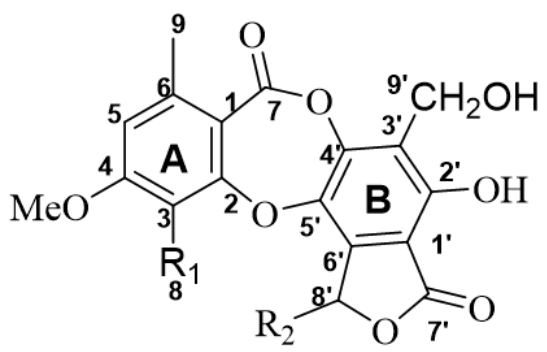

$6 \mathrm{R}^{1}: \mathrm{CHO} \quad \mathrm{R}^{2}$ : OMe

$7 \mathrm{R}^{1}: \mathrm{CHO} \quad \mathrm{R}^{2}: \mathrm{OH}$

$8 R^{1}: \mathrm{Me} \quad \mathrm{R}^{2}: \mathrm{OH}$

Figure 1. Chemical structures ofmethylstictic acid (1), stictic acid (2), cryptostictic acid (3), 8'-Omethylmenegazziaic acid (4), menegazziaic acid (5), 8'-O-methylconstictic acid (6), constictic acid (7), andhypoconstictic acid (8).

EA-L3.1-4 by CC. Purification of the fraction EA-L3.3 (1.2 g) resulted in three compounds: 3 (12.2 $\mathrm{mg})$, 5 (9.5 mg), and 8 (6.8 $\mathrm{mg})$.

8'-Methylstictic acid (1). White amorphous powder; for the ${ }^{1} \mathrm{H}$ and ${ }^{13} \mathrm{C}$ NMR (DMSO- $d_{6}$ ) spectroscopic data, see Tables 1 and 2.

Stictic acid (2). White amorphous powder; for the ${ }^{1} \mathrm{H}$ and ${ }^{13} \mathrm{C}$ NMR (DMSO- $d_{6}$ ) spectroscopic data, see Tables 1 and 2.

Cryptostictic acid(3). White amorphous powder; for the ${ }^{1} \mathrm{H}$ and ${ }^{13} \mathrm{C}$ NMR (DMSO- $d_{6}$ ) spectroscopic data, see Tables 1 and 2.

8'-O-Methylmenegazziaic acid(4). White amorphous powder; for the ${ }^{1} \mathrm{H}$ and ${ }^{13} \mathrm{C}$ NMR (DMSO- $d_{6}$ ) spectroscopic data, see Tables 1 and 2.

Menegazziaic acid (5). White amorphous powder; for the ${ }^{1} \mathrm{H}$ and ${ }^{13} \mathrm{C}$ NMR (DMSO- $\left.d_{6}\right)$ spectroscopic data, see Tables 1 and 2.

8'- $\boldsymbol{O}$-methylconstictic acid (6). White amorphous powder; for the ${ }^{1} \mathrm{H}$ and ${ }^{13} \mathrm{C}$ NMR (DMSO- $d_{6}$ ) spectroscopic data, see Tables 1 and 2.

Constictic acid (7). White amorphous powder; for the ${ }^{1} \mathrm{H}$ and ${ }^{13} \mathrm{C}$ NMR (DMSO- $d_{6}$ ) spectroscopic data, see Tables 1 and 2.

Hypoconstictic acid (8). White amorphous powder; for the ${ }^{1} \mathrm{H}$ and ${ }^{13} \mathrm{C}$ NMR (DMSO- $d_{6}$ ) spectroscopic data, see Tables 1 and 2.

\section{Results and Discussion}

Compound 1 was obtained as a white amorphous powder. The ${ }^{1} \mathrm{H}$ NMR and HSQC spectra of 1 showed the presence of one formyl $\left(\delta_{H} 10.41,1 \mathrm{H}, \mathrm{s}\right)$, one aromatic proton $\left(\delta_{H} 7.10,1 \mathrm{H}, \mathrm{s}\right)$, one acetal proton $\left(\delta_{H}\right.$ $6.47,1 \mathrm{H}, \mathrm{s})$, two methoxy groups $\left(\delta_{H} 3.92,3 \mathrm{H}, \mathrm{s}\right.$ and $\left.3.44,3 \mathrm{H}, \mathrm{s}\right)$, and two methyl groups $\left(\delta_{H} 2.49,3 \mathrm{H}\right.$, $\mathrm{s}$ and $2.19,3 \mathrm{H}, \mathrm{s})$. The ${ }^{13} \mathrm{C}$ NMR spectrum combining with HSQC spectrum confirmed the presence of twenty carbons comprising one aldehyde carbon $\left(\delta_{C} 186.7\right)$, two carbonxyl carbons $\left(\delta_{C} 165.9\right.$ and 160.6), twelve aromatic carbons $\left(\delta_{C} 162.7,162.4,152.4,151.0,148.3,133.1,132.6,121.7,114.3,112.9,113.2\right.$, and 108.8), one acetal carbon $\left(\delta_{C} 99.9\right)$, two methoxy groups ( $\delta_{C} 56.8$ and 56.3.), and two methyls $\left(\delta_{C}\right.$ 21.5 and 9.7). The HMBC correlations from $\mathrm{H}-5\left(\delta_{H} 7.10\right), 4-\mathrm{OCH}_{3}\left(\delta_{H} 3.85\right)$, and 3-CHO $\left(\delta_{H} 10.41\right)$ to $\mathrm{C}-4\left(\delta_{C} 162.7\right)$, and from $\mathrm{H}-5$ and $\mathrm{H}_{3}-9\left(\delta_{H} 2.49\right)$ to $\mathrm{C}-1\left(\delta_{C} 113.2\right.$, defined the connectivity through 
C-3-C-4-C-5-C-6-C-1 in A-ring. Moreover, a long range HMBC correlation between H-5 and C-7 ( $\delta$ 160.6) suggested the presence of the depsidone scaffold of 1 . The ${ }^{1} \mathrm{H}_{\mathrm{NMR}}$ chemical shift of $\mathrm{H}_{3}-9^{\prime}$ along with the HMBC correlations between $\mathrm{H}_{3}-9$ ' and C-2' $\left(\delta_{C} 151.0\right)$, C-3' $\left(\delta_{C} 121.7\right)$, and C-4' $\left(\delta_{C} 148.3\right)$ confirmed the connectivity C-2'-C-3'-C-4'. In addition, the HMBC correlations between H-9' and C-7' $\left(\delta_{C}\right.$ 165.9) and 8'-O-Me $\left(\delta_{C}\right.$ 56.3) led to deduction of the five-member ring lactone in the B-ring. The comparison of NMR data of $\mathbf{1}$ and those of methylstictic acid Ramesh and Baig (1994); Kathirgamanathar et al. (2005) showed that they were identical. Thus, 1 was elucidated as 8'-O-methylstictic acid.

Table 1. Proton nuclear magnetic resonance data of compounds 1 - $\mathbf{8}^{*}$

\begin{tabular}{|c|c|c|c|c|c|c|c|c|}
\hline $\mathbf{N}$ & $\begin{array}{c}\mathbf{1} \\
\delta \mathbf{H}, \mathbf{J} \\
(\mathbf{H z})\end{array}$ & $\begin{array}{c}\mathbf{2} \\
\delta \mathbf{H}, \mathbf{J} \\
(\mathbf{H z})\end{array}$ & $\begin{array}{c}\mathbf{3} \\
\delta \mathbf{H}, \mathbf{J} \\
\mathbf{( H z})\end{array}$ & $\begin{array}{c}\mathbf{4} \\
\delta \mathbf{H}, \mathbf{J} \\
(\mathbf{H z})\end{array}$ & $\begin{array}{c}\mathbf{5} \\
\delta \mathbf{H}, \mathbf{J} \\
(\mathbf{H z})\end{array}$ & $\begin{array}{c}\mathbf{6} \\
\delta \mathbf{H}, \mathbf{J} \\
(\mathbf{H z})\end{array}$ & $\begin{array}{c}\mathbf{7} \\
\delta \mathbf{H}, \mathbf{J} \\
(\mathbf{H z})\end{array}$ & $\begin{array}{c}\mathbf{8} \\
\delta \mathbf{H}, \mathbf{J} \\
(\mathbf{H z})\end{array}$ \\
\hline 5 & $7.10 \mathrm{~s}$ & $7.10 \mathrm{~s}$ & $6.95 \mathrm{~s}$ & $6.85 \mathrm{~s}$ & $6.82 \mathrm{~s}$ & $7.11 \mathrm{~s}$ & $7.08 \mathrm{~s}$ & $6.87 \mathrm{~s}$ \\
\hline 8 & $10.41 \mathrm{~s}$ & $10.45 \mathrm{~s}$ & $\begin{array}{c}4.80 \mathrm{~d}, 11.2 \\
4.62 \mathrm{~d}, 11.2\end{array}$ & & $9.10 \mathrm{~s}$ & $10.41 \mathrm{~s}$ & $10.42 \mathrm{~s}$ & $2.23 \mathrm{~s}$ \\
\hline $\begin{array}{c}9 \\
3-\mathrm{OH}\end{array}$ & $2.49 \mathrm{~s}$ & $2.48 \mathrm{~s}$ & $2.45 \mathrm{~s}$ & $\begin{array}{l}2.33 \mathrm{~s} \\
9.38 \mathrm{~s}\end{array}$ & $2.30 \mathrm{~s}$ & $2.49 \mathrm{~s}$ & $2.46 \mathrm{~s}$ & $2.39 \mathrm{~s}$ \\
\hline $\begin{array}{c}\text { 4- } \\
\text { OMe }\end{array}$ & $3.92 \mathrm{~s}$ & $3.89 \mathrm{~s}$ & $3.87 \mathrm{~s}$ & $3.84 \mathrm{~s}$ & $3.81 \mathrm{~s}$ & $3.92 \mathrm{~s}$ & $3.88 \mathrm{~s}$ & $3.85 \mathrm{~s}$ \\
\hline $\begin{array}{l}\text { 8' } \\
\text { 0, }\end{array}$ & $6.47 \mathrm{~s}$ & $6.60 \mathrm{br}$ & - & $6.47 \mathrm{~s}$ & $6.70 \mathrm{br}$ & $6.49 \mathrm{~s}$ & $6.62 \mathrm{br}$ & $6.67 \mathrm{br}$ \\
\hline $\begin{array}{c}9^{\prime} \\
8^{\prime}- \\
\text { OH }\end{array}$ & $2.19 \mathrm{~s}$ & $\begin{array}{l}2.17 \mathrm{~s} \\
8.19 \mathrm{br}\end{array}$ & $\begin{array}{l}2.19 \mathrm{~s} \\
8.22 \mathrm{br}\end{array}$ & $2.15 \mathrm{~s}$ & $\begin{array}{l}2.11 \mathrm{~s} \\
8.25 \mathrm{br}\end{array}$ & $4.64 \mathrm{~s}$ & $\begin{array}{l}4.60 \mathrm{~s} \\
8.25 \mathrm{br}\end{array}$ & $\begin{array}{l}4.60 \mathrm{~s} \\
8.29 \mathrm{br}\end{array}$ \\
\hline $\begin{array}{c}\text { 8'- } \\
\text { OMe }\end{array}$ & $3.44 \mathrm{~s}$ & & & $3.56 \mathrm{~s}$ & & $3.45 \mathrm{~s}$ & & \\
\hline
\end{tabular}

${ }^{*}$ These were recorded in DMSO- $\mathrm{d}_{6}$.

Compound 2 was isolated as a white amorphous powder. The ${ }^{1} \mathrm{H}$ NMR and ${ }^{13} \mathrm{C}$ NMR spectrum of 2 resembled those of $\mathbf{1}$, except for the presence of the hydroxy group $\left(\delta_{H} 8.19,1 \mathrm{H}, \mathrm{br}, 8\right.$ ' $\left.-\mathrm{OH}\right)$ and the absence of the methoxy group $\left(\delta_{H} 3.44\right.$ and $\delta_{C} 56.3,8$ '-O-Me), indicating the replacement of 8'-OH to 8'OMe in the lactone moiety in B-ring. The comparison of NMR data of 2 with those of stictic acid Dévéhat et al. (2007) showed that they were identical. Thus, $\mathbf{2}$ was concluded as stictic acid.

Compound 3 was acquired as a white amorphous powder. The ${ }^{1} \mathrm{H}$ NMR spectrum exhibited signals for seven resonances belonging to one hydroxy signal at $\delta_{H} 8.22$, two oxygenated methylene groups $\left(\delta_{H}\right.$ $4.80,1 \mathrm{H}, \mathrm{d}, 11.2$ and $4.62,1 \mathrm{H}, \mathrm{d}, 11.2)$, one methoxy moiety $\left(\delta_{H} 3.87,3 \mathrm{H}\right)$, and two methyl groups $\left(\delta_{H}\right.$ 2.45 and 2.19). The ${ }^{13} \mathrm{C}$ NMR spectrum displayed nineteen carbon signals, similar to those of compound 2 (Table 2), except for the appearance of the formyl group 8-CHO $\left(\delta_{H} 10.41,1 \mathrm{H}, \mathrm{s}\right)$ and the appearance of the oxygenated methylene $8-\mathrm{CH}_{2}-\mathrm{OH}\left(\delta_{C} 51.3\right)$ instead of the formyl group in A-ring. The ${ }^{1} \mathrm{H}$ and ${ }^{13} \mathrm{C}$ NMR spectra of $\mathbf{3}$ were identical to those of cryptostictic acid Shimada et al. (1980). Thus, compound 3 was elucidated as cryptostictic acid.

Compound 4 was isolated as a white amorphous powder. The ${ }^{1} \mathrm{H}$ NMR and HSQC spectra showed the presence of one hydroxy group at $\delta_{H} 9.38(1 \mathrm{H}, \mathrm{s})$, one aromatic proton at $\delta_{H} 6.85(1 \mathrm{H}, \mathrm{s})$, one acetal proton at $\delta_{H} 6.47(1 \mathrm{H}, \mathrm{s})$, two methoxy at $\delta_{H} 3.84(3 \mathrm{H}, \mathrm{s})$ and $3.56(3 \mathrm{H}, \mathrm{s})$, and two methyl groups at $\delta_{H} 2.33(3 \mathrm{H}, \mathrm{s})$ and $2.15(3 \mathrm{H}, \mathrm{s})$. In addition, the ${ }^{13} \mathrm{C} \mathrm{NMR}$ and HSQC spectra also revealed the characteristic resonances of a depsidone skeleton including two conjugated carbonyl carbons $\left(\delta_{C} 166.8\right.$ 
and 161.5), twelve aromatic carbons, one acetal carbon $\left(\delta_{C} 100.8\right)$, two oxygenated carbons $\left(\delta_{C} 56.7\right.$ and 56.3), and two methyl groups $\left(\delta_{C} 19.8\right.$ and 9.5). In the HMBC spectra, correlations between $\mathrm{H}-5\left(\delta_{H}\right.$ $6.85,1 \mathrm{H}, \mathrm{s}), 4-\mathrm{OMe}\left(\delta_{H} 3.84\right)$ and $\mathrm{C}-4\left(\delta_{C} 152.7\right)$, and of $\mathrm{H}-5, \mathrm{H}_{3}-9$ and $\mathrm{C}-1\left(\delta_{C} 113.3\right)$, identified the connectivity through $\mathrm{C}-1-\mathrm{C}-6-\mathrm{C}-5-\mathrm{C}-4$ in ring $\mathrm{A}$. The absence of formyl group (3-CHO) in accordance with the ${ }^{13} \mathrm{C}$ chemical shifts of C-2 (152.5), C-3 (135.0), and C-4 (152.5) defined the appearance of a hydroxyl group at $\mathrm{C}-3$ with its ${ }^{1} \mathrm{H}$ chemical shift as $\delta_{H} 9.38$, further confirmed by HMBC correlation between $\mathrm{H}-5$ and $\mathrm{C}-3\left(\delta_{C}\right.$ 135.0). The HMBC correlations between $\mathrm{H}_{3}-9$ ' to C-2' $\left(\delta_{C} 152.5\right), \mathrm{C}-3$ ' $\left(\delta_{C}\right.$ 121.2), and C-4' $\left(\delta_{C} 148.7\right)$, and from $\mathrm{H}-8$ ' to $\mathrm{C}-7^{\prime}\left(\delta_{C} 166.8\right)$ and 8'-OMe $\left(\delta_{C} 56.3\right)$, indicated that the B-ring of 4 was similar with those of $\mathbf{1}$. Detailed comparison of ${ }^{1} \mathrm{H}$ and ${ }^{13} \mathrm{C}$ NMR data of 4 with those of 8'-O-methylmenegazziaic acid Kathirgamanathar et al. (2005) gave close similarity, thus identifying 4 as 8'-O-methylmenegazziaic acid.

Table 2. Carbon-13 nuclear magnetic resonance data of compounds 1 - $8^{*}$

\begin{tabular}{ccccccccc}
\hline Position & $\mathbf{1}$ & $\mathbf{2}$ & $\mathbf{3}$ & $\mathbf{4}$ & $\mathbf{5}$ & $\mathbf{6}$ & $\mathbf{7}$ & $\mathbf{8}$ \\
\hline 1 & 112.9 & 113.1 & 111.6 & 113.6 & 113.3 & 113.1 & 114.4 & 110.8 \\
2 & 162.4 & 163.0 & 161.4 & 152.5 & 152.4 & 162.9 & 162.4 & 161.1 \\
3 & 114.3 & 114.5 & 118.5 & 135.0 & 138.2 & 114.4 & 114.5 & 114.5 \\
4 & 162.7 & 162.4 & 161.7 & 152.5 & 152.4 & 162.5 & 162.4 & 161.1 \\
5 & 113.2 & 112.8 & 112.7 & 111.7 & 111.7 & 113.4 & 112.8 & 112.5 \\
6 & 152.4 & 150.8 & 144.2 & 132.9 & 132.4 & 151.1 & 150.7 & 141.8 \\
7 & 160.6 & 160.7 & 158.9 & 161.7 & 161.4 & 160.6 & 160.6 & 158.7 \\
8 & 186.7 & 186.6 & 51.3 & & & 186.9 & 186.6 & 8.6 \\
9 & 21.5 & 21.5 & 20.8 & 19.9 & 19.8 & 21.6 & 21.4 & 20.7 \\
4-OMe & 56.8 & 56.8 & 56.2 & 56.3 & 56.2 & 56.5 & 56.8 & 56.2 \\
1' & 108.8 & 109.2 & 109.0 & 109.0 & 109.0 & 109.4 & 113.2 & 109.1 \\
2' & 151.0 & 152.0 & 151.5 & 151.4 & 151.4 & 153.2 & 152.7 & 152.3 \\
3' & 121.7 & 120.8 & 120.3 & 120.4 & 120.4 & 124.0 & 123.2 & 122.1 \\
4' & 148.3 & 148.0 & 148.2 & 148.3 & 148.3 & 148.6 & 148.2 & 148.3 \\
5' & 132.6 & 137.5 & 137.9 & 132.6 & 132.4 & 135.5 & 138.1 & 137.8 \\
6' & 133.1 & 135.9 & 135.8 & 135.1 & 134.9 & 137.6 & 137.4 & 136.9 \\
7' & 165.9 & 166.3 & 166.5 & 166.8 & 166.5 & 165.6 & 166.2 & 166.1 \\
8' & 99.9 & 95.1 & 95.4 & 100.7 & 95.4 & 99.9 & 95.3 & 95.3 \\
9' & 9.7 & 9.6 & 9.5 & 9.7 & 9.5 & 53.0 & 52.6 & 52.7 \\
8'-OMe & 56.3 & & & 56.7 & & 57.0 & & \\
\hline
\end{tabular}

*These were recorded in DMSO- $\mathrm{d}_{6}$.

Compound 5 was isolated as a white amorphous powder. Comparison of the 1D NMR data of 5 with those of 4 (Tables 1 and 2) showed that they were similar, except for the absence of one methoxy group at $\delta_{H} 3.56$ and $\delta_{C} 56.3$ (8'-OMe), suggesting the presence of 8'-OH in the lactone moiety in B-ring instead of 8 '-OMe. Comparison of NMR data of 5 with those of menegazziaic acid Hirayama et al. (1976) confirmed the chemical structure of $\mathbf{5}$ as menegazziaic acid.

Compound 6 was obtained as a white amorphous powder. Detailed comparison of the 1D NMR data of $\mathbf{6}$ with those of $\mathbf{1}$ showed that they were closely similar. The only difference was the replacement of an oxygenated methylene at $\mathrm{d}_{H} 4.65\left(\delta_{C} 53.0\right)$ for the methyl $\mathrm{H}_{3}-9^{\prime}\left(\delta_{H} 2.19\right.$ and $\left.\delta_{C} 9.7\right)$. The HMBC correlations between $\mathrm{H}_{2}-9^{\prime}(4.65,2 \mathrm{H}, \mathrm{s})$ and C-2' $\left(\delta_{C} 148.6\right), \mathrm{C}-3^{\prime}\left(\delta_{C} 124.0\right)$, and C-4' $\left(\delta_{C} 153.2\right)$ confirmed 

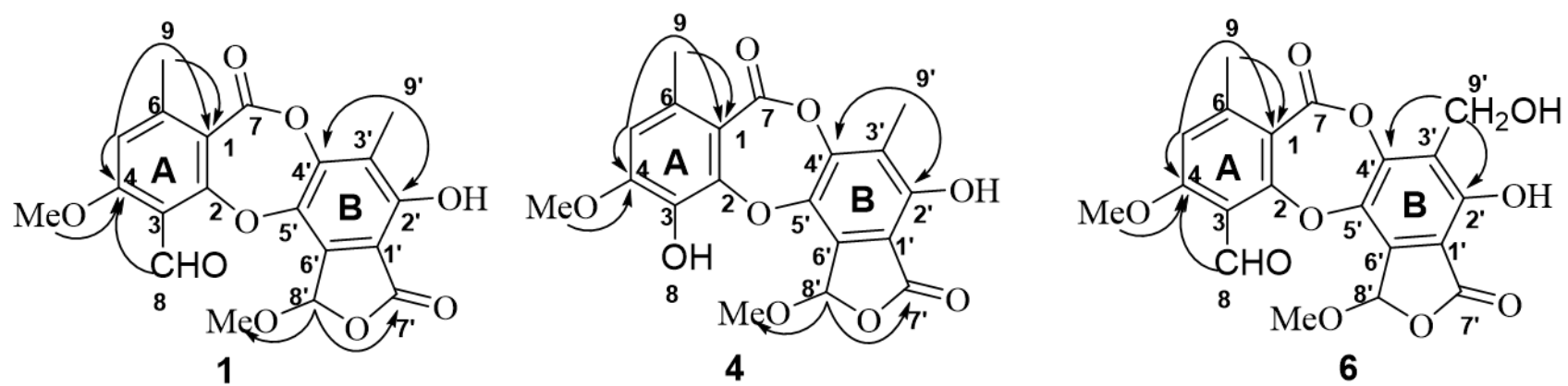

Figure 2. Key HMBC correlations of 1, 4, and 6.

its position in B-ring. The ${ }^{1} \mathrm{H}$ and ${ }^{13} \mathrm{C}$ NMR data of 6 were similar to those of 8 '- $O$-methylconstictic acid Papadopoulou et al. (2007). Thus, 6 was concluded to be 8'-O-methylconstictic acid.

Compound 7 was isolated as a white amorphous powder. The 1D NMR data of 7 closely resembled those of 6 (Tables 1 and 2) and indicated that they have the same scaffold, except for the absence of 8'OMe at $\delta_{H} 3.46\left(\delta_{C} 56.5\right)$. This implied that the 8'-OMe in 6 was replaced by 8 '-OH in 7. The NMR data of 7 were identical to those of constictic acid Shimada et al. (1980). Consequently, the chemical structure of 7 was elucidated as constictic acid.

Compound 8 was obtained as white amorphous powder. Analysis of the ${ }^{1} \mathrm{H}$ and ${ }^{13} \mathrm{C}$ NMR data of 8 showed similar resonances to those of 7 (Tables 1 and 2), except for the replacement of the formyl group at $\mathrm{C}-3$ by the methyl group $\left(\delta_{H} 2.23\right.$, s and $\left.\delta_{C} 8.6\right)$ in the A-ring. The NMR data of 8 were identical with those of hypoconstictic acid Elix et al. (1985). Thus, the structure of $\mathbf{8}$ was elucidated as hypoconstictic acid.

Stictic acid 2 and its derivatives 1, 3-8 were found in many lichens belonging to Usnea and Lobaria genera Nguyen et al. (2017); Dévéhat et al. (2007). Such compounds are superoxide anion scavengers and are as potent as ascorbic acid but show no toxicity on some human cell lines Ismed et al. (2017). Din et al. Din et al. (2010) reported the presence of three depsidones (salazinic acid, norstitic acid, and protocetraric acid) in $U$. baileyi by HPLC analysis without the isolation of compounds. Among the isolated compounds, 2 was reported as a major component Din et al. (2010) while other compounds 1, 3-8 were found in Usnea baileyi for the first time.

\section{Conclusion}

From Usnea baileyi collected in the Lam Dong Province, eight compounds were isolated and elucidated, including methylstictic acid (1), stictic acid (2), cryptostictic acid(3), 8'-O-methylmenegazziaic acid(4), menegazziaic acid (5), 8'-O-methylconstictic acid (6), constictic acid (7), and hypoconstictic acid (8). Compounds 1, 3-8 were isolated in $U$. baileyi for the first time.

\section{Abbreviations}

${ }^{13}$ C NMR: Carbon-13 nuclear magnetic resonance; ${ }^{1} \mathbf{H}$ NMR: Proton nuclear magnetic resonance; CC: column chromatography ; DMSO: Dimethyl sulfoxide $\left(\mathrm{CD}_{3} \mathrm{SOCD}_{3}\right)$; HMBC: Heteronuclear multiple bond correlation; HPLC: High-performance liquid chromatography; HSQC: Heteronuclear single quantum coherence ; TLC: Thin layer chromatography 


\section{Conflicts of interest}

The authors declare no competing financial interest.

\section{Author contribution}

Nguyen V.K. has contributed in conducting experiments, acquisition of data and compose the manuscript. Duong T. H. made substantial contributions to interpretation of data, searching the bibliography and gave final approval of the manuscript to be submitted.

\section{Acknowledgements}

We are grateful to Ms. Natwida Dangphui for authentification the scientific name of the lichen.

\section{References}

Boustie, J. and Grube, M. (2005). Lichens-a promising source of bioactive secondary metabolites. Plant Genetic Resources, 3(2):273-287.

Dévéhat, F. L.-L., Tomasi, S., Elix, J. A., Bernard, A., Rouaud, I., Uriac, P., and Boustie, J. (2007). Stictic acid derivatives from the lichen usnea articulata and their antioxidant activities. Journal of natural products, 70(7):1218-1220.

Din, L. B., Zakaria, Z., Samsudin, M. W., and Elix, J. A. (2010). Chemical profile of compounds from lichens of bukit larut, peninsular malaysia. Sains Malaysiana, 39(6):901-908.

Duong, T. H., Huynh, B. L. C., Chavasiri, W., Chollet-Krugler, M., Nguyen, T. H. T., Hansen, P. E., Pogam, P. L., Thüs, H., Boustie, J., Nguyen, K. P. P., et al. (2017). New erythritol derivatives from the fertile form of roccella montagnei. Phytochemistry, 137:156-164.

Elix, J. A., Gaul, K. L., and James, P. W. (1985). $\alpha$-acetylhypoconstictic acid, a new depsidone from the lichen menegazzia dispora. Australian journal of chemistry, 38(11):1735-1737.

Hirayama, T., Fujikawa, F., Yosioka, I., and Kitagawa, I. (1976). On the constituents of the lichen in the genus menegazzia. menegazziaic acid, a new depsidone from menegazzia asahinae (yas. ex zahlbr.) sant. and menegazzia terebrata (hoffm.) mass. Chemical and Pharmaceutical Bulletin, 24(10):2340-2344.

Ismed, F., Dévéhat, F. L.-L., Rouaud, I., Ferron, S., Bakhtiar, A., and Boustie, J. (2017). Nmr reassignment of stictic acid isolated from a sumatran lichen stereocaulon montagneanum (stereocaulaceae) with superoxide anion scavenging activities. Zeitschrift für Naturforschung C, 72(1-2):55-62.

Kathirgamanathar, S., Williams, D. E., Andersen, R. J., Bombuwela, K., Silva, D. D., and Karunaratne, V. (2005). $\beta$-orcinol depsidones from the lichen usnea sp. from sri lanka. Natural product research, 19(7):695-701.

Müller, K. (2001). Pharmaceutically relevant metabolites from lichens. Applied Microbiology and Biotechnology, 56(1-2):9-16.

Nguyen, D. M., Do, L. M., Nguyen, V. T., Chavasiri, W., Mortier, J., and Nguyen, P. P. (2017). Phenolic compounds from the lichen lobaria orientalis. Journal of natural products, 80(2):261-268.

Papadopoulou, P., Tzakou, O., Vagias, C., Kefalas, P., and Roussis, V. (2007). $\beta$-orcinol metabolites from the lichen hypotrachyna revoluta. Molecules, 12(5):997-1005.

Ramesh, P. and Baig, E. S. A. (1994). Chemical investigation of south indian lichens: Ramalina species. Indian Drugs-Bombay-, 31:445-445. 
Shimada, S., Saitoh, T., Sankawa, U., and Shibata, S. (1980). New depsidones from lobaria oregana. Phytochemistry, 19(2):328-330.

Yang, D.-M., Takeda, N., Iitaka, Y., Sankawa, V., and Shibata, S. (1973). The structures of eumitrins a1, a2 and b: The yellow pigments of the lichen, usnea bayleyi (stirt.) zahlbr. Tetrahedron, 29(3):519528. 